\title{
ENSINO CRÍTICO DE INGLÊS E FORMAÇÃO DOCENTE NA CONTEMPORANEIDADE
}

\section{ENGLISH CRITICAL PEDAGOGY AND TEACHER CONTEMPORARY EDUCATION}

\author{
FINARDI, Kyria Rebeca \\ kyria.finardi@gmail.com \\ UFES - Universidade Federal do Espírito Santo \\ VIEIRA, Gicele Vergine \\ gicelevpreb@gmail.com \\ IFC - Instituto Federal Catarinense
}

RESUMO Este estudo reflete sobre o ensino de Inglês e a formação docente no contexto no Brasil do século XXI. Para tanto, o estudo revisa o conceito de pedagogia crítica discutindo suas implicações para o ensino-aprendizagem de Inglês como Língua Estrangeira (LE). A fim de subsidiar a reflexão proposta, o artigo analisa qualitativamente crenças de licenciandos em Química que cursam a disciplina de Inglês Instrumental e licenciandos em Letras Inglês sobre o papel do professor e do Inglês em suas formações e na educação contemporânea. Em geral, a análise de dados indica que o professor é visto como mero transmissor de conhecimentos e que o Inglês tem um papel secundário na sua formação, e consequentemente, na constituição identitária do futuro professor.

PALAVRAS-CHAVE: Educação contemporânea. Ensino crítico de Inglês. Formação docente.

ABSTRACT The study reflects about English critical teaching and teacher training in the Brazilian educational context of the twenty-first century. The concept of critical pedagogy is reviewed discussing its implications for English as a Foreign Language (FL) teaching and learning. In order to support the proposed reflection, the article analyzes the beliefs of Chemistry undergraduate students who were attending EFL classes and the beliefs of English Teaching undergraduate students regarding the role of English in their training and contemporary education. Overall data analysis indicates that the teacher is seen as a mere transmitter of knowledge and English is seen as having a secondary role in education, and hence in the identity constitution of future teachers.

KEYWORDS: Contemporary education. English critical pedagogy. Teacher education.

\section{INTRODUÇÃO}


Atos de Pesquisa em Educação - ISSN 1809-0354

Blumenau - vol. 11, n. 2, p.549-571 ago./nov. 2016

DOI: http://dx.doi.org/10.7867/1809-0354.2016v11n2p549-571

A pedagogia crítica de Paulo Freire defende o desenvolvimento da capacidade de agentes educacionais de pensarem criticamente sobre seu universo e suas relações sociais nele a fim de tornarem-se agentes de sua própria história (FREIRE, 1996; 2003). Essa visão de educação rejeita a ideia de transferência de conhecimentos sugerindo, ao invés disso, uma co-construção de conhecimento libertador e participativo, socialmente situado. Partindo da pedagogia crítica de Freire é plausível sugerir que o ensino crítico de língua estrangeira - LE (neste caso, o Inglês) - deveria se preocupar com a construção de um raciocínio crítico em e sobre o Inglês. Em outras palavras, essa pedagogia crítica de inglês não pode se traduzir na prática, infelizmente tão comum, de ensinar vocabulário e gramática em LE na esperança de que, transferindo conteúdos linguísticos suficientes para a "conta" dos alunos, eles tenham saldo suficiente para bancar (construir) o aprendizado dessa língua, usando-a de forma emancipadora.

Pesquisas na área de linguística aplicada e de psicolinguística voltadas para o aprendizado de línguas estrangeiras (por exemplo FINARDI, 2010a; MCLAUGHLIN, 1990; MCLAUGHLIN; HEREDIA, 1996) mostram que a aquisição de uma LE é um fenômeno complexo cuja linha de aprendizado não é constante nem ascendente como gostariam de imaginar os professores que trabalham no paradigma de ensino conteudista, depositando conteúdos linguísticos na conta dos alunos com a esperança de que eles tenham saldo suficiente no final do "depósito" para bancar seu desempenho na LE. Contrariamente à expectativa desses professores, essas pesquisas (por exemplo MCLAUGHLIN, 1990) mostram que a linha de aprendizado de uma LE se assemelha mais à letra $U$, onde a base equivale ao período de reestruturação da língua, durante o qual o desempenho na LE piora após o aprendizado de novas estruturas linguísticas.

Assim, a psicolinguística descreve a linha de aprendizado em LE como tendo um desempenho inicial rápido e ascendente, piorando durante a fase intermediária quando novos itens são aprendidos e tem que ser acomodados no sistema em construção. Durante o período de reestruturação (ou acomodação de novos itens no sistema) o desempenho piora, voltando a melhorar uma vez que essas novas estruturas tenham sido incorporadas ao repertório linguístico do aprendiz (FINARDI, 2010a; MCLAUGHLIN, 
Atos de Pesquisa em Educação - ISSN 1809-0354

Blumenau - vol. 11, n. 2, p.549-571 ago./nov. 2016

DOI: http://dx.doi.org/10.7867/1809-0354.2016v11n2p549-571

1990).

Se entendermos que o aprendizado de uma língua estrangeira é um fenômeno muito mais complexo do que o idealizado pela metáfora do depósito bancário, podemos sugerir que se faz necessária uma reflexão acerca de uma pedagogia crítica para o ensino de línguas estrangeiras especialmente quando essa língua vem carregada de crenças e ideologias como é o caso do Inglês como LE no Brasil (por exemplo FINARDI; FERRARI, 2008; FINARDI, 2014). Assim, quando a LE em questão é o Inglês, é necessário refletir não apenas sobre o papel desse idioma no século XXI, mas também sobre a identidade e a formação do professor em geral e do professor de Inglês em particular.

Dois fatores importantes no processo de construção da identidade docente são as crenças e os modelos criados pelos alunos e futuros professores durante sua trajetória escolar e formação. Em relação às crenças, vários autores na área de Linguística Aplicada (por exemplo PAJARES, 1992; BARCELOS, 2000; BARCELOS, 2004; FINARDI, 2010b) sugerem que o interesse em estudar crenças de professores tem aumentado em razão da possibilidade de entender melhor a prática docente por meio do entendimento das crenças que a subjazem.

Crenças podem ser definidas como avaliações, julgamentos, ideias e conhecimento que podem ser expressos na prática. Pajares (1992) faz distinção entre crenças e conhecimento, afirmando que as primeiras são baseadas em avaliações e julgamentos enquanto o segundo é baseado em fatos objetivos. De qualquer forma, Pajares (1992) reconhece a dificuldade de distinguir entre os dois conceitos na prática. $\mathrm{Na}$ área de ensino de línguas, Barcelos (2001) define crenças como opiniões e ideias que alunos e professores têm sobre o processo de ensino-aprendizagem. Segundo Pajares (1992) e Barcelos (2001), a investigação das crenças de alunos e professores pode nos ajudar a entender como esses sujeitos tomam certas decisões e em última instância, moldam sua prática e identidade.

A constituição identitária do professor não inicia apenas no momento em que este se insere em um programa de formação inicial (curso de licenciatura), porém muito antes disso, refletindo provavelmente em sua concepção de educação, ensino, aprendizagem 
Atos de Pesquisa em Educação - ISSN 1809-0354

Blumenau - vol. 11, n. 2, p.549-571 ago./nov. 2016

DOI: http://dx.doi.org/10.7867/1809-0354.2016v11n2p549-571

e mais especificamente no seu papel enquanto profissional do magistério. No caso da formação do professor de Inglês, as crenças sobre o papel desse idioma e sua função na construção de uma cidadania global também afetam a identidade do professor e 0 resultado do ensino.

Enraizadas à identidade docente estão as dúvidas quanto aos saberes que o professor deve dominar a fim de exercer seu fazer profissional. Ora, se o futuro docente não tem clareza do seu papel no meio social e educacional em que se insere, é provável que este viva um conflito em relação ao que ensinar, para que ensinar e como ensinar. Oliariet al (2012) nos alertam para o fato de que esses conflitos constituem parte da construção da identidade docente. A realidade da sala de aula exige do professor mais do que o domínio técnico do conteúdo, dadas as peculiaridades e complexidades do ensinar e do aprender.

Segundo Tardif (2007, p. 41), o fazer pedagógico se constitui da articulação de diferentes saberes dentre os quais estão os saberes disciplinares, os curriculares e os experienciais. No caso do professor de línguas, o conhecimento teórico ao qual tem acesso durante sua formação tem valor temporário e só pode ser validado por meio da prática na atuação profissional. Essa prática moldará novas concepções teóricas, já que determinará uma reflexão do profissional acerca da tensão entre suas práticas e as teorias adquiridas.

Para a pedagogia crítica de Freire, a formação docente deve ir além das fronteiras do domínio técnico, dando conta das relações historicamente construídas pelos atores do processo educativo de tal sorte a situar o conhecimento emancipador dos agentes educacionais. Segundo Freire (1996, p. 134):

Não importa em que sociedade estejamos, em que mundo nos encontremos, não é possível formar engenheiros ou pedreiros, físicos ou enfermeiros, dentistas ou torneiros, educadores ou mecânicos, agricultores ou filósofos, pecuaristas ou biólogos sem uma compreensão de nós mesmos enquanto seres históricos, políticos, sociais e culturais; sem uma compreensão de como a sociedade funciona. $E$ isto o treinamento supostamente apenas técnico não dá.

Ao pensarmos em uma pedagogia crítica de ensino de LE, neste caso, do Inglês, 
Atos de Pesquisa em Educação - ISSN 1809-0354

Blumenau - vol. 11, n. 2, p.549-571 ago./nov. 2016

DOI: http://dx.doi.org/10.7867/1809-0354.2016v11n2p549-571

não podemos deixar de considerar o papel que este idioma tem no mundo contemporâneo, onde profundas mudanças paradigmáticas têm sido estimuladas pela globalização, pelo desenvolvimento tecnológico e científico, e pelo uso desse idioma (por exemplo FINARDI, 2014; FINARDI; ORTIZ, 2015; FINARDI; PORCINO, 2014).

No contexto educacional brasileiro, professores ainda se questionam sobre o seu papel em relação a essa língua e seu uso e ensino (por exemplo FINARDI; FERRARI, 2008). Desta forma, a fim de refletir sobre uma pedagogia crítica que abarque as discussões sobre o ensino de Inglês no Brasil contemporâneo e sua relação com a formação da identidade docente, é preciso analisar crenças de professores e a formação dessas crenças em futuros professores já que a maior parte do conhecimento pedagógico vem de teorias sobre o aprendizado que estão mais focadas nos resultados do aprendizado do que no processo de tomada de decisão e construção de conhecimento docente (GATBONTON, 1999; BINNIE-SMITH, 1996). Binnie-Smith (1996) nos alerta para o fato de que professores experientes se baseiam mais em suas crenças do que em teorias recebidas durante sua formação. Como as crenças de professores afetam a prática e a construção da identidade docente, elas devem ser constantemente avaliadas para garantir uma educação emancipadora e crítica.

Cientes da importância de estudar a formação de crenças e identidades docentes, pesquisadores têm dedicado esforços para entender como os professores sabem o que sabem (por exemplo SCHON, 1995), como constroem suas filosofias e teorias de ensino e aprendizagem (por exemplo CLANDININ; CONNELLY, 1987) e no caso do ensino de Inglês, suas crenças sobre o papel dessa língua e do seu ensino no Brasil (por exemplo FINARDI; PORCINO, 2015). As crenças de professores e futuros professores podem ser analisadas tanto por meio do discurso quanto da prática desses agentes (por exemplo FINARDI; PORCINO; FADINI; ALENCAR, no prelo).

De acordo com Larsen-Freeman (1991) as pesquisas sobre crenças de professores são escassas e insuficientes para garantir uma prática docente informada e crítica e nesse sentido este estudo oferece uma contribuição por meio da reflexão sobre o papel do Inglês no mundo e na formação e prática docente ao analisar crenças de futuros professores de Inglês e de Química sobre o papel desse idioma em suas 
Atos de Pesquisa em Educação - ISSN 1809-0354

Blumenau - vol. 11, n. 2, p.549-571 ago./nov. 2016

DOI: http://dx.doi.org/10.7867/1809-0354.2016v11n2p549-571

formações e práticas docentes. Para tanto, o método usado para analisar as crenças desses professores em formação será descrito no que segue.

\section{MÉTODO}

Este estudo é de cunho qualitativo (DORNYEI, 2007) e tem como objetivo analisar crenças de futuros professores de Inglês e de Química - atuais aprendizes de Inglês como LE - no contexto educacional brasileiro a fim de refletir sobre uma possível pedagogia crítica de Inglês e suas implicações para a formação docente em geral. Para tanto, foram analisadas respostas de um questionário aplicado a 12 alunos da disciplina de Inglês Instrumental do curso de Licenciatura em Química de um Instituto Federal de Educação, Ciência e Tecnologia; e notas de campo tomadas durante as observações das aulas da disciplina de Estágio Supervisionado do curso de Licenciatura em Letras Inglês de uma Universidade Federal. Ambas as instituições de ensino onde o estudo foi realizado compõem a rede federal de educação superior brasileira e ofertam cursos de formação de professores em diversas áreas.

\section{RESULTADOS E DISCUSSÃO}

O questionário aplicado aos alunos do curso de Licenciatura em Química tinha como objetivo principal promover a reflexão a respeito da disciplina de Inglês Instrumental e suas possíveis contribuições para o futuro licenciado em Química. Na primeira subseção, apresentamos as crenças dos alunos da disciplina de Inglês Instrumental do curso de Química coletadas por meio desse questionário e na segunda subseção, discorremos sobre as reflexões de futuros docentes de Letras Inglês coletadas durante as observações das aulas da disciplina de Estágio Supervisionado curricular do curso de Licenciatura em Letras Inglês.

\subsection{CRENÇAS DE LICENCIANDOS EM QUÍMICA E ALUNOS DE INGLÊS INSTRUMENTAL}


Atos de Pesquisa em Educação - ISSN 1809-0354

Blumenau - vol. 11, n. 2, p.549-571 ago./nov. 2016

DOI: http://dx.doi.org/10.7867/1809-0354.2016v11n2p549-571

A primeira pergunta do questionário indagou os alunos a respeito do grau de importância da disciplina de Inglês Instrumental no curso de Licenciatura em Química e pediu que os respondentes justificassem suas respostas. As respostas deveriam ser geradas a partir de uma escala progressiva de cinco níveis, na qual o primeiro nível equivalia à opção "nada importante" e o último à opção "extremamente importante". Sete dos doze participantes responderam que a disciplina de Inglês Instrumental é de extrema importância para o futuro docente de Química, enquanto que outros quatro alunos assinalaram o nível 4 da escala e apenas um assinalou o nível 3, o qual pode ser interpretado como o nível equivalente a uma importância mediana na escala proposta. Podemos observar no Quadro 1 as justificativas dos alunos em relação ao nível de importância da disciplina de Inglês Instrumental por eles determinado.

Analisando as justificativas dos futuros docentes de Química no Quadro 1, podemos perceber que, com exceção dos Participantes $F$ e L, para metade dos alunos o aprendizado de Inglês se limita ao conhecimento da língua pela língua, sem vislumbrar outras implicações que podem decorrer do fato de dominarem um idioma com o status e a amplitude do Inglês para as relações sociais e profissionais no atual cenário mundial. Em outras palavras, esses alunos parecem não compreender o aprendizado de Inglês como uma forma de ampliação do seu capital social ${ }^{1}$, ou ainda como um instrumento de mudança do fazer pedagógico, capaz de dar ao futuro docente novas ferramentas para o desenvolvimento de uma postura mais crítica perante as mudanças científicotecnológicas, econômicas e sociais do século XXI.

A visão refletida nas respostas de grande parte dos alunos analisados parece indicar que o ensino-aprendizagem de Inglês é visto por eles como um mero coadjuvante na formação profissional docente e não como uma forma de educação emancipadora e crítica que permite aos indivíduos exercer suas cidadanias de forma global e plena por

1Warschauer $(2003,2006)$ conceitua capital social como sendo a capacidade que indivíduos tem de criar benefícios para si e para suas comunidades por meio de suas relações sociais e Finardi, Prebianca e Momm (2013) entendem que o ensino de inglês pode ajudar na inclusão social, no desenvolvimento do capital social e de uma cidadania global. 
Atos de Pesquisa em Educação - ISSN 1809-0354

Blumenau - vol. 11, n. 2, p.549-571 ago./nov. 2016

DOI: http://dx.doi.org/10.7867/1809-0354.2016v11n2p549-571

meio do uso do Inglês não só para acessar informação técnica em uma área específica mas também e talvez mais importante, para produzir e intercambiar informação e conhecimento de forma global.

Ainda sobre a mesma pergunta, outros alunos - Participantes A, D, E e G, por exemplo - apresentaram justificativas que parecem ser mais coerentes com o conceito de capital social proposto por Warschauer (2003, 2006), uma vez que mostraram compreender que o aprendizado de Inglês Ihes permitirá participar de uma rede mundial de comunicação e interação capaz de agregar valor à sua carreira profissional fornecendo acesso a outros níveis de conhecimento tais como publicações internacionais na área de Química.

Porém, curiosamente, nenhum dos alunos mencionou a contribuição do aprendizado de Inglês para a formação docente especificamente. Ou seja, nas justificativas apresentadas, os alunos não deixam claro como o conhecimento dessa LE pode influenciar sua prática e seu pensar docente. Entendemos que o docente deve se atualizar constantemente sobre pesquisas em suas áreas de ensino e, portanto, independente da área de ensino na qual o docente atue, o Inglês deveria possibilitar uma melhor atualização para esse docente, uma vez que grande parte dos trabalhos científicos e acadêmicos estão publicados em Inglês (GRADDOL, 2006).

Um dos motivos pelos quais a formação docente não tenha sido mencionada pode estar ligado às questões inerentes à construção da identidade do professor. Como esses alunos se vêm enquanto docentes de Química? Qual seu papel na sociedade contemporânea? Como entendem o fazer pedagógico na sua área do conhecimento? Ainda que não seja possível afirmar o que os alunos quiseram dizer ao usar a palavra "profissional" (ser ou não um bom professor), ousamos especular que a falta de respostas para todas as perguntas que aqui levantamos parece indicar que esses futuros professores não veem o papel do professor ligado ao papel do pesquisador que tem que se atualizar em seu campo de atuação. As respostas analisadas aqui parecem sugerir que esses futuros professores de química veem seu papel de professor como sendo o de transmissor de informações e de conteúdos de química que não precisam ser revistos ou atualizados necessariamente pelo professor. 
Atos de Pesquisa em Educação - ISSN 1809-0354

Blumenau - vol. 11, n. 2, p.549-571 ago./nov. 2016

DOI: http://dx.doi.org/10.7867/1809-0354.2016v11n2p549-571

Se pensarmos no papel do Inglês como instrumento de formação de capital social e de cidadania global conforme sugerem Finardi, Prebianca e Momm (2013) podemos também inferir, com base nos dados deste estudo, que alguns dos futuros professores de Química participantes deste estudo não vêm a relação entre língua inglesa e o conteúdo que eles ensinam para essa formação de capital social e de cidadania global. A exceção seriam os participantes $A, D, E, G$, J e K que parecem ver no Inglês um papel mais próximo do descrito acima. No Quadro que segue as respostas dadas pelos estudantes de Inglês Instrumental do curso de Licenciatura em Química para a pergunta sobre a importância do Inglês em sua vida profissional são apresentadas.

Quadro 1 - Justificativa para o nível de importância da disciplina de Inglês Instrumental

\begin{tabular}{|c|c|}
\hline Participante & Justificativa \\
\hline A & $\begin{array}{l}\text { Muitos artigos científicos na área de química são escritos em Inglês, rótulos } \\
\text { de produtos, manual de operação de equipamentos de laboratório também } \\
\text { são escritos em Inglês, fazendo necessário ter o conhecimento. }\end{array}$ \\
\hline B & Aprendi a identificar e interligar algumas palavras no texto \\
\hline C & Será necessário para a área de Química \\
\hline D & $\begin{array}{l}\text { O Inglês tem papel fundamental na Química por se tratar de uma matéria } \\
\text { universal, para que o conhecimento possa ser difundido por mais de uma } \\
\text { forma }\end{array}$ \\
\hline $\mathrm{E}$ & $\begin{array}{l}\text { Extremamente importante o Inglês é uma matéria necessária pois muitos } \\
\text { artigos, livros e sites estão em Inglês }\end{array}$ \\
\hline $\mathrm{F}$ & No decorrer da nossa vida profissional vamos precisar muito do Inglês \\
\hline G & $\begin{array}{l}\text { É importante pois já tive situações de montagem de equipamentos } \\
\text { laboratoriais com manuais em Inglês e muitos textos e artigos só estão } \\
\text { disponíveis em Inglês }\end{array}$ \\
\hline $\mathrm{H}$ & O Inglês é essencial para futuros químicos \\
\hline I & $\begin{array}{l}\text { Para estimular a leitura do Inglês e a pesquisa do significado dos termos } \\
\text { desconhecidos }\end{array}$ \\
\hline$J$ & $\begin{array}{l}\text { Além de ser uma língua mundial, muitos dos melhores livros e artigos da área } \\
\text { são em Inglês. }\end{array}$ \\
\hline K & $\begin{array}{l}\text { Porque as melhores pesquisas na área de Química estão publicadas em } \\
\text { Inglês, isso nos ajuda um pouco na compreensão desses artigos. }\end{array}$ \\
\hline $\mathrm{L}$ & Para ser um bom profissional \\
\hline
\end{tabular}

Fonte: Das autoras

A segunda pergunta do questionário aplicado aos licenciandos em Química que cursavam a disciplina de Inglês Instrumental objetivou identificar qual habilidade do idioma deveria ser o foco da disciplina na opinião dos alunos: leitura (reading), escrita (writing), fala (speaking) ou audição (listening).

A maioria dos alunos (nove dos doze participantes) respondeu que a leitura 
Atos de Pesquisa em Educação - ISSN 1809-0354

Blumenau - vol. 11, n. 2, p.549-571 ago./nov. 2016

DOI: http://dx.doi.org/10.7867/1809-0354.2016v11n2p549-571

deveria ser o foco da disciplina devido à sua importância para o futuro químico. Assim como na pergunta sobre a importância do Inglês para o futuro professor de Química, novamente, nenhuma menção foi feita à formação docente ou ao professor de Química e sim ao profissional de química de tal sorte que não podemos saber se as respostas se referem ao químico apenas ou ao professor de Química também. Com base nessas respostas inferimos que aparentemente, esses alunos não se percebem como futuros docentes, mas sim como futuros químicos ou técnicos em química. Tal fato parece refletir um problema inerente aos cursos de Licenciatura como veremos adiante na análise das crenças dos licenciandos em Letras Inglês.

As habilidades de escrita e de fala foram citadas por dois participantes e apenas um respondeu que as quatro habilidades deveriam ser atendidas pela disciplina. Vale ressaltar aqui que, aparentemente, o principal objetivo da disciplina de Inglês Instrumental, de acordo com a maioria das respostas fornecidas pelos participantes, parece ser o ensino da leitura. Cardoso (2012) nos alerta para a necessidade de rever esse entendimento, uma vez que o ensino de Inglês para fins específicos não precisa resumir-se apenas ao ensino de vocabulário e técnicas de leitura. Entretanto, a maioria dos cursos de Inglês Instrumental tem esse foco no Brasil, talvez pela herança de políticas linguísticas e parâmetros educacionais nacionais para o ensino de línguas estrangeiras como os contidos na Lei de Diretrizes e Bases da Educação e nos Parâmetros Curriculares Nacionais que sugerem que o ensino de línguas estrangeiras tenha como foco principal a leitura na língua alvo.

A terceira pergunta do questionário preocupou-se com as técnicas ou estratégias de ensino/aprendizagem que o professor de Inglês Instrumental deveria utilizar em sala de aula a fim de desenvolver a habilidade que o aluno considerou a mais importante (conforme informado na questão 2). A maioria (oito dos doze participantes) respondeu que a estratégia mais adequada seria a interpretação textual confirmando a resposta sobre a habilidade mais importante a ser trabalhada no curso de Inglês Instrumental. Entre esses oito respondentes, um indicou preferência pela tradução de textos. Um aluno sugeriu o uso de vídeos e outro ainda o uso de música e filmes. Dois alunos não souberam responder essa questão. 
Atos de Pesquisa em Educação - ISSN 1809-0354

Blumenau - vol. 11, n. 2, p.549-571 ago./nov. 2016

DOI: http://dx.doi.org/10.7867/1809-0354.2016v11n2p549-571

É interessante ressaltar que apenas as estratégias sugeridas pelos participantes F e L (vídeos e música e filme, respectivamente) se aproximaram do uso das novas tecnologias de informação e comunicação (NTICs) para o ensino-aprendizagem de Inglês com LE; nenhuma outra sugestão foi feita sobre a inclusão de recursos tecnológicos para promover o aprendizado de Inglês como língua estrangeira. Tal fato parece indicar que, apesar de viver em um mundo altamente informatizado e conectado, os futuros docentes de Química parecem não ver as NTICs como recursos tecnológicos com potencial pedagógico para o ensino-aprendizado de Inglês. Nesse sentido esses resultados vão contra a sugestão de Finardi e Porcino (2014) de que as tecnologias em geral e a internet em particular mudaram a forma de usarmos, aprendermos e ensinarmos o Inglês.

A quarta e última pergunta do questionário aplicado aos licenciandos em química perguntou aos alunos acerca do papel do professor de Inglês Instrumental na formação profissional do futuro docente de Química. As respostas podem ser observadas no Quadro 2.

Ao analisarmos as respostas dos alunos à questão 4, notamos que cinco alunos consideram o papel do professor de Inglês Instrumental importante, mas de forma geral, a fala dos alunos indica que esse profissional é visto principalmente como um instrumentalizador, responsável por fornecer aos alunos as ferramentas necessárias para aprender o léxico, aprender a ler e compreender textos na língua alvo de forma mais rápida e eficiente. Este argumento parece evidente na fala do participante $L$, que alega que o a função do professor de Inglês é "Instruir o aluno".

A discussão sobre a função dos professores no mundo internetizado (FINARDI; PREBIANCA; MOMM, 2013) de hoje é bastante abrangente, porém parece haver um consenso de que instruir, ensinar e educar não são a mesma coisa (por exemplo, FINARDI; DALVI, 2013). Os dados deste estudo parecem indicar que o papel do professor de inglês é visto pelos futuros professores de Química como sendo o de mero instrutor. A diferença entre o instrutor, professor e educador será abordada mais adiante quando falarmos sobre a visão dos futuros professores de Inglês no tocante ao seu papel.

Novamente parece oportuno questionar qual conceito de docência/docente sustenta tal afirmação (de que o papel do professor é instruir o aluno). Está claro para o 
Atos de Pesquisa em Educação - ISSN 1809-0354

Blumenau - vol. 11, n. 2, p.549-571 ago./nov. 2016

DOI: http://dx.doi.org/10.7867/1809-0354.2016v11n2p549-571

aluno (ou para os alunos) que o curso de licenciatura forma professores? O que significa ser licenciado em Química? Tais indagações nos conduzem mais uma vez a questões identitárias de grande relevância e que aparentemente ainda se encontram sem resposta, pelo menos no contexto analisado. No que segue, o Quadro 2 apresenta as respostas dos licenciandos em Química sobre o papel do professor de Inglês. Notem que com exceção do participante $E$, novamente vemos a expressão do químico mais frequentemente e evidentemente nos dados do que a do professor de Química, o que reforça a questão levantada acima sobre como os licenciandos de Química se vêm e constroem sua identidade como professores de Química.

Quadro 2 - Opinião dos alunos sobre o papel do professor de Inglês Instrumental na formação do docente de Química

\begin{tabular}{|c|l|}
\hline Participante & \multicolumn{1}{c|}{ Opinião dos participantes } \\
\hline A & $\begin{array}{l}\text { O professor de Inglês tem um papel importante, tendo em vista a necessidade } \\
\text { do mercado para área dos químicos }\end{array}$ \\
\hline B & $\begin{array}{l}\text { Fundamental, pois é a base do nosso aprendizado, onde podemos tirar } \\
\text { dúvidas }\end{array}$ \\
\hline C & Importante \\
\hline D & Com o pouco tempo das aulas não teve uma grande colaboração \\
\hline E & $\begin{array}{l}\text { Tem um papel muito importante como espelho pois o aluno de licenciatura se } \\
\text { espelha em todos os professores e a matéria é muito importante para a } \\
\text { formação do profissional pois o Inglês é a língua mais usada em todo o mundo }\end{array}$ \\
\hline F & Importante \\
\hline G & Direcionar uma boa interpretação de textos e fácil compreensão também \\
\hline H & $\begin{array}{l}\text { O professor de Inglês é essencial porque tem algumas técnicas, conceitos que } \\
\text { temos que entender em Inglês }\end{array}$ \\
\hline I & $\begin{array}{l}\text { Apresentar pelo menos o básico de vocabulário científico, auxiliando na } \\
\text { pesquisa de artigos, por exemplo }\end{array}$ \\
\hline J & $\begin{array}{l}\text { Ensinar o aluno a ler, interpretar textos em Inglês, usando métodos que } \\
\text { facilitem o aprendizado e diminua o tempo de resolução da mesma }\end{array}$ \\
\hline K & $\begin{array}{l}\text { Formar ou pelo menos dar uma base para ajudar a compreender artigos em } \\
\text { Inglês voltados para área de química }\end{array}$ \\
\hline L & Instruir o aluno \\
\hline
\end{tabular}

Fonte: Das autoras

Apenas um dos participantes $(E)$ identificou o professor como espelho para o aluno de licenciatura. Essa fala nos faz refletir sobre a importância da observação do fazer docente durante a formação do licenciando. Os modelos pedagógicos aos quais esses alunos são submetidos não se referem apenas às técnicas e estratégias de ensinoaprendizagem, mas também refletem as representações mentais, os conceitos, as 
Atos de Pesquisa em Educação - ISSN 1809-0354

Blumenau - vol. 11, n. 2, p.549-571 ago./nov. 2016

DOI: http://dx.doi.org/10.7867/1809-0354.2016v11n2p549-571

crenças, as ideologias dos professores responsáveis pela formação do futuro docente, contribuindo, ainda que implicitamente, para a construção de sua identidade enquanto professor.

Cabe ressaltar que esses modelos nem sempre contribuem de forma positiva para a formação do aluno observador. Muitas vezes, exemplos adquiridos de professores podem influenciar o futuro professor negativamente ou contribuir para uma exacerbação da figura do professor enquanto detentor supremo do conhecimento, estimulando uma educação transmissiva e não crítica (FREIRE, 1996, 2003) como a que propomos combater. Além disso, não raras são as vezes em que os alunos não se identificam com o professor por algum motivo de ordem pessoal e ou de personalidade, ou simplesmente por não gostarem da disciplina que esse professor leciona. Como exposto por Marcelo (2009, p. 03),

A identidade docente vai se configurando assim, de forma paulatina e pouco reflexiva através do que poderíamos denominar aprendizagem informal e mediante a observação em futuros professores que vão recebendo modelos docentes com os quais se vão identificando pouco a pouco, e em cuja identificação influem mais os aspectos emocionais que os racionais.

Independentemente de como se constrói a identidade docente do professor de Química, os dados deste estudo parecem apontar para a conclusão de que o papel do Inglês e do professor de Inglês na formação do professor de Química são periféricos e instrumentais. No que segue, analisaremos as crenças que formam a construção identitária de futuros professores de Inglês.

\subsection{CRENÇAS DOS FUTUROS PROFESSORES DE INGLÊS}

Durante as observações da disciplina de estágio supervisionado do curso de Licenciatura em Letras Inglês, foram identificadas algumas questões relevantes para a reflexão proposta neste estudo que serão divididas em quatro subseções, descritas no que segue. A primeira delas se relaciona ao papel do Inglês no mundo atual.

\subsubsection{Inglês - Língua Estrangeira ou Língua Internacional?}


Atos de Pesquisa em Educação - ISSN 1809-0354

Blumenau - vol. 11, n. 2, p.549-571 ago./nov. 2016

DOI: http://dx.doi.org/10.7867/1809-0354.2016v11n2p549-571

Logo no primeiro encontro presencial da disciplina de Estágio Supervisionado de Inglês onde as observações foram feitas, surgiu uma discussão com relação ao status (e consequente terminologia que deveria se adotar) desse idioma no Brasil e no mundo. Diferentes terminologias associadas ao Inglês como língua estrangeira, segunda língua, língua adicional, língua franca, entre outras, foram discutidas chegando-se à conclusão de que no Brasil o Inglês tem status de língua estrangeira nas escolas públicas (onde o ensino de inglês tem a mesma carga horária e recebe o mesmo tratamento de outras línguas estrangeiras) e de língua internacional nas escolas privadas (onde a língua estrangeira ensinada é, em geral, o Inglês e a carga horária é maior do que nas escolas públicas). Vale ressaltar que a distinção entre língua estrangeira e língua internacional nesse contexto se ateve e relaciona à função da língua (JORDÃO, 2014) e ao status que ela parece ter em uma determinada comunidade (GIMENEZ, 2013).

Em decorrência da necessidade de aumentar a carga horária do ensino de Inglês nas escolas públicas a fim de refletir o status que essa língua deveria ter na opinião dos licenciandos em Letras Inglês, outra questão, de ordem metodológica, se contrapõe: como alcançar esse status frente à legislação vigente? A LDB prevê que uma (nosso grifo) língua estrangeira (não necessariamente o Inglês), seja ensinada a partir do $5^{\circ}$. Ano. Apesar da maior parte das escolas públicas oferecer aulas de Inglês (e não de outras línguas estrangeiras), a carga horária designada a esse idioma é, em geral, de duas aulas de 50 minutos por semana, ou seja, compatível com uma carga horária de língua estrangeira e não de língua internacional (GIMENEZ, 2013; FINARDI, 2014). Um idioma internacional, na opinião dos licenciandos observados, deveria ter uma carga horária equivalente ao idioma nacional, já que seria usada em contextos nacionais e transnacionais, para interagir com brasileiros e estrangeiros, nativos e não nativos, cujas línguas maternas são diferentes ou não (JORDÃO, 2014).

$\mathrm{Na}$ esteira das discussões sobre qual metodologia de ensino de Inglês poderia abarcar o status desse idioma como língua internacional, surgiu uma possível saída para driblar o status do Inglês como língua estrangeira e o consequente problema de falta de carga horária para o ensino de Inglês como língua internacional. Trata-se da sugestão de 
Atos de Pesquisa em Educação - ISSN 1809-0354

Blumenau - vol. 11, n. 2, p.549-571 ago./nov. 2016

DOI: http://dx.doi.org/10.7867/1809-0354.2016v11n2p549-571

uso de uma metodologia de ensino de línguas por meio de conteúdos diversos, descrita a seguir.

3.2.2 Metodologia de ensino de línguas por meio do ensino de outros conteúdos

A metodologia de ensino de inglês por meio de conteúdos diversos, conhecida em inglês com diferentes terminologias como ContentlanguageTeaching (CLT), ContentBasedInstruction (CBI), EnglishMediumInstruction (EMI) ou ContentandLanguagelntegrated Learning (CLIL), sugere que o professor dê aula de conteúdos diversos, na língua alvo. Essa metodologia se casa muito bem com o convite à interdisciplinaridade feito pelas orientações curriculares para o ensino de línguas estrangeiras e pelos parâmetros curriculares nacionais para línguas estrangeiras uma vez que permite que o professor de inglês, em parceria com o professor de geografia, por exemplo, dê aula de conteúdos de geografia, como países e continentes, em inglês. A diferença é que nessa metodologia o Inglês seria o meio e não o conteúdo.

Por meio dessa metodologia é possível aumentar o tempo de exposição do aluno ao idioma alvo (através da parceria com outros professores de outras disciplinas), ajudando o aluno a pensar em conteúdos diversos (e relevantes) em Inglês, maximizando assim o aprendizado tanto do conteúdo quanto do meio. Essa metodologia foi discutida durante as aulas da disciplina de Estágio Supervisionado de Inglês observadas como uma forma de combater a reduzida carga horária dedicada ao ensino de Inglês nas escolas públicas.

Durante as sessões de reflexão entre professor supervisor e estagiários, foi observado que apesar da proposta de interdisciplinaridade e ensino de conteúdos diversos em Inglês ter sido bem aceita pelos futuros professores de Inglês, na prática 0 sucesso dessas aulas depende sempre do entendimento sobre interdisciplinaridade e do engajamento com a causa de, pelo menos, dois professores de disciplinas diferentes. Outra questão levantada pelos futuros professores de inglês durante as discussões sobre a metodologia CLIL se refere à necessidade de maior investimento na formação docente para que professores de língua possam dar aula de conteúdos diversos por meio da 
Atos de Pesquisa em Educação - ISSN 1809-0354

Blumenau - vol. 11, n. 2, p.549-571 ago./nov. 2016

DOI: http://dx.doi.org/10.7867/1809-0354.2016v11n2p549-571

língua e vice-versa.

A discussão sobre o conteúdo a ser ensinado nas aulas de Inglês tratada nas sessões de reflexão entre professor supervisor e estagiários de Letras Inglês deu margem, por sua vez, a outra discussão pertinente - a do papel do professor em geral e do professor de Inglês em especial. Essa questão é tratada na próxima subseção.

\subsubsection{Instrutor, professor ou educador?}

Em meio à discussão sobre o método de ensino de Inglês baseado em conteúdos diversos descrita acima, um aluno perguntou: "But if we don't teach English but teach in English instead... what do we really teach?" (Se não ensinamos inglês, mas em vez disso ensinamos em inglês, o que nós ensinamos afinal?). Essa pergunta deu origem à discussão sobre o papel do professor de Inglês nesse novo paradigma metodológico vislumbrado durante as discussões nas aulas da disciplina de Estágio Supervisionado do curso investigado.

Alguns alunos comentaram que para que o professor de Inglês ensinasse outros conteúdos, como por exemplo de Artes, ele teria que ser um expert em Artes. Foi esclarecido que a proposta dessa metodologia era a de interdisciplinaridade de tal forma que o professor de Inglês não teria que se tornar um expert em Artes assim como o professor dessa disciplina não tinha que ser fluente em inglês; bastava que ambos colaborassem na construção dos conteúdos a serem ensinados nas duas disciplinas. Obviamente que essa colaboração dependeria do conhecimento de cada professor em conteúdos outros o que nos remete à sugestão dada anteriormente de um maior investimento na formação docente em geral.

A questão do conteúdo a ser ensinado deu margem à discussão de quais temas ou conteúdos deveriam então ser ensinados pelo professor de Inglês especificamente. Nessa fase da discussão o professor da disciplina de Estágio Supervisionado retomou a lição do mestre Paulo Freire sugerindo que o professor deveria ser antes de tudo, um educador. Isso implicaria em ensinar conteúdos que fossem importantes para a formação dos alunos para a vida. A diferença entre um professor e um educador, segundo se 
Atos de Pesquisa em Educação - ISSN 1809-0354

Blumenau - vol. 11, n. 2, p.549-571 ago./nov. 2016

DOI: http://dx.doi.org/10.7867/1809-0354.2016v11n2p549-571

conclui nessa discussão, é que o professor é expert em ensinar o seu conteúdo enquanto que o educador está mais preocupado com a formação do indivíduo para o exercício pleno da cidadania do que com a transmissão de conteúdos específicos.

Assim, o papel do professor de Inglês foi desconstruído ao longo das discussões da disciplina do Estágio Supervisionado de Letras Inglês seguindo o raciocínio de que o professor de Inglês dá aula de regras gramaticais e vocabulário em Inglês e nesse sentido, é um instrutor. Ao extrapolar o ensino de regras gramaticais e vocabulário para incluir a reflexão sobre a linguagem em si o instrutor de Inglês se torna professor de Inglês. Depois de discutir metodologias críticas vemos o papel do professor que não é mais o de um professor de Inglês, mas o de um professor que dá aula em Inglês. Finalmente, o papel do professor foi sendo desconstruído e construído para entender que ele não deveria se limitar a dar aula de Inglês, mas sim educar para a vida, através do Inglês. Foi um longo trajeto percorrido nas discussões sobre o papel do professor para ir de instrutor a professor de Inglês e finalmente a educador, em Inglês.

A título de ilustração citamos um exemplo de como se deu essa desconstrução para um grupo de futuros professores que entregou (para avaliação), um plano de aula elaborado pelo grupo e que aparentava ser muito bom do ponto de vista técnico, ao professor supervisor. O plano de aula tinha objetivos, conteúdo, suposições, materiais, chaves de respostas, referências e cópias das atividades, além de trabalhar com conteúdos de outras disciplinas (tecnologia e física), como sugerido pelo professor supervisor. Entretanto, o tema abordado (telefones celulares), não era tratado de forma crítica.

O tema foi usado como pretexto para trabalhar o vocabulário em inglês referente a números, preços, valores e funções de um celular, sem tratar da dimensão crítica do uso dessa tecnologia nos dias atuais, como por exemplo, questões sobre o que seria um bom uso do celular, seus pontos positivos e negativos. Ao revisar o plano de aula o professor supervisor questionou os alunos sobre possibilidades de ensinar valores e princípios éticos de cidadania, através do uso de celulares. A partir da discussão o plano de aula foi completamente refeito para educar os estudantes, e não informar e instruir somente, a respeito do bom uso de telefones celulares, por meio do inglês. 
Atos de Pesquisa em Educação - ISSN 1809-0354

Blumenau - vol. 11, n. 2, p.549-571 ago./nov. 2016

DOI: http://dx.doi.org/10.7867/1809-0354.2016v11n2p549-571

A reflexão sobre como usar celulares, feita durante a elaboração de planos de aula dessa equipe, gerou outra discussão, a da pertinência e relevância da inclusão de novas tecnologias na educação em geral e no ensino de Inglês especificamente. Esse o tema da próxima e última subseção.

\subsubsection{Inclusão social, Inglês e tecnologia}

Outro tema discutido nas aulas da disciplina de Estágio Supervisionado de Inglês que merece destaque aqui é o do papel do Inglês e da tecnologia como linguagens (passaportes) de inclusão social. Segundo Finardi, Prebianca e Momm (2013), no mundo globalizado quem não fala Inglês e não é digitalmente letrado está excluído de várias formas de mediação de conhecimento através da linguagem - seja ela a linguagem tecnológica ou o Inglês como língua internacional predominante na internet.

Nesse sentido, foi proposto à turma do estágio supervisionado de Inglês que fossem incorporadas algumas possibilidades da internet 2.0 sugeridas nesse artigo (FINARDI; PREBIANCA; MOMM, 2013) nos planos de aula elaborados pelos estagiários para o ensino do idioma, usando abordagens híbridas que incorporam o uso de NTICs no processo de ensino-aprendizagem de inglês (por exemplo GRAHAM, 2006; FINARDI, 2012) a fim de desenvolver o letramento digital e o letramento linguístico global como formas de inclusão social.

A sugestão foi acatada pelos alunos que produziram planos de aula usando quatro possibilidades da internet 2.0, uma para cada habilidade trabalhada. Para desenvolver as habilidades de compreensão e produção oral foram propostas diversas atividades usando Podcasts e a ferramenta Voicethread que permite a interação assíncrona via oral. Para desenvolver as habilidades de leitura e escrita de forma integrada foram propostas atividades usando duas ferramentas da web - a Wikipédia e o Google Translator e a metodologia Webquest, conforme FINARDI; PORCINO, 2013.

A inclusão dessas ferramentas tecnológicas teve um impacto positivo tanto no professor regente quanto nos alunos que frequentaram a aula de Inglês conduzida de acordo com esses planos de aula. Durante as observações das aulas regidas pelos 
Atos de Pesquisa em Educação - ISSN 1809-0354

Blumenau - vol. 11, n. 2, p.549-571 ago./nov. 2016

DOI: http://dx.doi.org/10.7867/1809-0354.2016v11n2p549-571

futuros professores de inglês durante a disciplina de Estágio Supervisionado nas escolas públicas, os alunos fizeram comentários favoráveis ao uso dessa nova "metodologia", descrita pelos alunos (estudantes do ensino fundamental) como uma forma de ensinar e falar a mesma língua que eles.

De forma geral, os dados coletados durante a observação das aulas da disciplina de Estágio Supervisionado de Letras Inglês do curso investigado neste estudo apontam para a conclusão de que os futuros professores de Inglês observados neste estudo, ao menos no início das discussões realizadas durante as aulas da disciplina de Estágio Supervisionado, não se veem como educadores, mas como transmissores de conhecimento, ou seja, como instrutores. Talvez essa visão se relacione ao papel do inglês no ensino regular e em cursos livres.

A análise das observações da disciplina de Estágio Supervisionado de Inglês mostrou também que os futuros professores entendem que no Brasil o Inglês tem status de língua estrangeira na educação regular e de língua internacional nos institutos e escolas de idioma, o que afeta significativamente a visão deles próprios enquanto professores e falantes não nativos de Inglês nesses contextos. Finalmente, apesar dos futuros professores de Inglês defenderem que o uso da metodologia CLIL e a inclusão das NTICs no ensino de Inglês são pertinentes, eles alertam que é necessário um maior investimento na formação e educação docente para que essa implementação e inclusão possam ocorrer.

\section{CONCLUSÃo}

Este estudo refletiu sobre o ensino crítico de Inglês e a formação docente. Para tanto, crenças sobre o papel do Inglês e do professor de Inglês foram analisadas da perspectiva dos alunos da disciplina de Inglês Instrumental do curso de licenciatura em Química e da perspectiva de alunos da disciplina de Estágio Supervisionado do curso de Licenciatura em Letras Inglês.

A análise de dados sugere que a visão dos participantes deste estudo ainda 
Atos de Pesquisa em Educação - ISSN 1809-0354

Blumenau - vol. 11, n. 2, p.549-571 ago./nov. 2016

DOI: http://dx.doi.org/10.7867/1809-0354.2016v11n2p549-571

parece ser a de que o professor é apenas um transmissor de conhecimentos, um instrutor (ou depositário, na metáfora Freiriana de ensino bancário) e que o Inglês e a tecnologia tendem a ter um papel secundário na formação do seu capital social docente, e consequentemente, na constituição identitária do futuro professor.

Nesse sentido, importa ressaltar que os currículos dos cursos de licenciatura merecem revisão para incluir disciplinas críticas e de formação e capacitação docente para o uso do Inglês e das tecnologias de forma crítica, contribuindo para a formação de capital social docente para o mundo contemporâneo.

\section{KYRIA REBECA FINARDI}

Mestre e Doutora em Letras Inglês e Literatura Correspondente pela UFSC, professora do Departamento de Linguagens, Cultura e Educação e dos Programas de Linguística (PPGEL) e Educação (PPGE) da Universidade Federal do Espirito Santo (UFES).

\section{GICELEVERGINE VIEIRA}

Mestre e Doutora em Letras Inglês e Literatura Correspondente pela UFSC. Professora do Instituto Federal Catarinense - Campus Blumenau.

\section{REFERÊNCIAS}

BARCELOS, A. M. F. Understanding teachers' and students' language learning beliefs in experience: a dewey an approach. 2000. Tese (doutorado). The University of Alabama, Tuscaloosa.

BARCELOS, A. M. F. Crenças sobre aprendizagem de línguas, Lingüística Aplicada e ensino de línguas. Revista Linguagem \& Ensino, v. 7, n. 1, p. 123-156, 2012.

BARCELOS, A. M. F. Metodologia de pesquisa das crenças sobre aprendizagem de línguas: estado da arte. Revista Brasileira de Linguística Aplicada, v. 1, n. 1, p. 71-92, 2001.

BINNIE-SMITH, D. Teacher decision making in the ESL classroom. In D.Freeman\& J. Richards (Eds), Teacher learning in language teaching. Cambridge: Cambridge University Press, 1996.

CLANDININ, D.J.; CONNELY, F.M. Narrative, experience and the study of curriculum. Washington, DC: The American Association of Colleges or Teacher Education, 1987. 
Atos de Pesquisa em Educação - ISSN 1809-0354

Blumenau - vol. 11, n. 2, p.549-571 ago./nov. 2016

DOI: http://dx.doi.org/10.7867/1809-0354.2016v11n2p549-571

CARDOSO, G. L. The effects of CALL on L2 vocabulary acquisition: an exploratory study. 2012.Tese (doutorado). Universidade Federal de Santa Catarina. Programa de PósGraduação em Letras/Inglês e Literatura Correspondente. Florianópolis, Santa Catarina.

DORNYEI, Z. Research methods in applied linguistics: Quantitative, qualitative and mixed methodologies. Oxford: Oxford University Press, 2007.

FINARDI, K.; FERRARI, L. Reflecting on the English(es) taught in Brazil.Crop (FFLCH/USP), v. 13, p. 205-214, 2008.

FINARDI, K. Working Memory Capacity in Second Language Learning. 1. ed. Saarbrucken: Lambert Academic Publishing AG \& Co.KG, v. 1. 217pp,2010b.

FINARDI, K. Teachers' beliefs on and use of ludic language in the EFL class. 1. ed. Lambert Academic Publishing AG \& Co.KG, 2010a.

FINARDI, K. Technology and L2 learning: hybridizing the curriculum. In: Language and Literature in the Age of Technology- Anais do III Congressolnternacional da ABRAPUI. Beck, M. S.; Silveira, R.; Funck, S. B.; Xavier, R. P. (Orgs.). Florianópolis: Universidade Federal de Santa Catarina, v. 1. pp. 1-8, 2012.

FINARDI, K. The slaughter of Kachru's five sacred cows in Brazil and the use of English as an international language. Studies of English Language Teaching, v. 2, p. 401-411, 2014.

FINARDI, K.; PORCINO, M.C. Internet tools in the design of a task cycle for L2 teaching. Revista Contextos Linguísticos, v. 7, p. 273-291, 2013.

FINARDI, K.;PREBIANCA, G.; MOMM, C. F. Tecnologia na Educação: o caso da internet e do Inglês como linguagens de inclusão. Cadernos do IL, n. 46, p. 193-208, 2013.

FINARDI, K.; DALVI, M. A. Crenças de professores de línguas sobre a formação inicial e continuada. Glauks (UFV), v. 13, p. 113-134, 2013.

FINARDI, K.; PORCINO,M.C. Tecnologia e Metodologia no Ensino de Inglês: Impactos da Globalização e da Internacionalização. Ilha do Desterro, v. 66, p. 239-284, 2014.

FINARDI, K. R.; PORCINO, M. C. O papel do inglês na formação e na internacionalização da educação no Brasil. Revista Horizontes de Linguística Aplicada, ano 14, n.1, p. 109134, 2015.

FINARDI, K. R.; PORCINO, M.C.; FADINI, K.; ALENCAR, J.G. Formação de professores de Inglês para o Brasil do século XXI: refletindo sobre as crenças de futuros professores sobre o uso de tecnologia e da metodologia CLILno ensino de Inglês. Revista Brasileira 
Atos de Pesquisa em Educação - ISSN 1809-0354

Blumenau - vol. 11, n. 2, p.549-571 ago./nov. 2016

DOI: http://dx.doi.org/10.7867/1809-0354.2016v11n2p549-571

de Educação. No prelo, 2016.

FINARDI, K.; ORTIZ, R. A. Globalization, Internationalization and Education: What is the Connection? IJAEDU- International E-Journal of Advances in Education, v. 1, p. 18-25, 2015.

FREIRE, P. Pedagogia da autonomia: saberes necessários à prática educativa. 34. ed. São Paulo: Paz e Terra,1996.

FREIRE, P. Pedagogia do Oprimido. 3. ed. Rio de Janeiro: Paz e Terra, 2003.

GATBONTON, E. Investigating experienced ESL teachers' pedagogical knowledge. The Modern Language Journal, 83 (1), 35-50,1999.

GIMENEZ, T. A ausência de políticas para o ensino da língua inglesa nos anos iniciais de escolarização no Brasil. In: NICOLAIDES;SILVA; TíTLIO;ROCHA. (Org.). Política e políticas linguísticas. 1. ed. Campinas: Pontes Editores, 2013. p. 199-218.

GRADDOL, D. English Next. London: British Council, 2007.

GRAHAM, C. Blended Learning Systems: definition, current trends, future directions. In: BONK, Curtis; GRAHAM, Charles (Eds.). Handbook of Blended Learning: global perspectives, local designs. San Francisco, CA: Pfeiffer Publishing, 2006. pp.41-54.

JORDÃO, C. M. ILA - IFL - ILE- ILG: Quem dá conta? Revista Brasileira de Linguística Aplicada,v.14, n.1, p.13-40, 2014.

LARSEN-FREEMAN, D. Second Language Acquisition Research: Staking out the Territory. TESOL Quarterly, 25:315-50, 1991.

MARCELO, C. Identidade docente: constantes e desafios. Revista Brasileira de Pesquisa sobre Formação de professores, v. 01, n. 01, p. 109-131, ago./dez. 2009. Disponível em http://formacaodocente.autenticaeditora.com.br.

MCLAUGHLIN, B. Restructuring. Applied Linguistics, 11(2), p. 113-128, 1990.

MCLAUGHLIN, B.; HEREDIA, R. Information-processing approaches to research on second language acquisition and use. In B. W. RITCHIE, T. (Ed.), Handbook of second language acquisition (pp. 213-228). San Diego: Academic Press, 1996.

OLIARI, F. A. S.et al. Refletindo sobre a identidade e a formação do professor da Educação Superior. Educação em foco. UNISEPE, v.5, p. 01-13, 2012.

PAJARES, M. F. Teachers' beliefs and educational research: cleaning up a messy construct. Review of educational research, v. 62, n. 3, p. 307-332, 1992. 
Atos de Pesquisa em Educação - ISSN 1809-0354

Blumenau - vol. 11, n. 2, p.549-571 ago./nov. 2016

DOI: http://dx.doi.org/10.7867/1809-0354.2016v11n2p549-571

SCHÖN, D. Formar professores como profissionais reflexivos In: NÓVOA, A.Os Professores e sua Formação. Portugal (Lisboa): Publicações Dom Quixote, 1995.

TARDIF, M. Saberes docentes e formação profissional.8. ed. Petrópolis: Vozes, 2007.

WARSCHAUER, M. Social capital and access. Universal Access in the Information Society, 2, 2003.

WARSCHAUER, M.Tecnologia e inclusão social: a exclusão digital em debate. São Paulo: SENAC, 319 p., 2006.

Artigo recebido em maio de 2015.

Aprovado em maio de 2016.

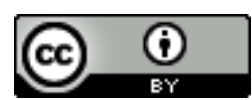

Este trabalho está licenciado com uma Licença Creative Commons - Atribuição 4.0 Internacional 